\title{
Assessing Student's Speaking Through Socratic Questioning Method
}

\author{
Woro Kusmaryani \\ English Department, Borneo University, Tarakan, Indonesia \\ lunasaski@gmail.com
}

\begin{abstract}
Socratic questioning is a method of learning introduced by Socrates where a series of questions are used in the conversation or debate which carried out by two or more people who discuss and confront the issues. The purpose of the research is to describe the use of Socratic questioning in assessing student's speaking at fourth semester students of Borneo University Tarakan Academic Year 2014/2015. This research used descriptive qualitative design which collected documents, observation, and interview as the data. This research was done in speaking class at fourth semester students of Borneo University Tarakan. The data was analysed qualitatively and the analysis process cover data collection, data reduction, data display, and conclusion drawing/verification. The result shows that student's speaking result reaches the expectation of the lecturer where $31 \%$ students got $\mathrm{A}, \mathbf{3 8 \%}$ students got $\mathrm{B}+$, and $31 \%$ students got B. Interview result shows that the lecturer said that Socratic questioning not only can be used to assess student's skill in speaking but also their critical thinking although some obstacles faced such as; issues selection, types of Socratic questions used in assessing, lecturer preparation, and time consuming.
\end{abstract}

Keywords: Speaking, Socratic Questioning Method, Critical Thinking.

\section{INTRODUCTION}

Speaking is a complex area of language acquisition. A lot of students have spent years studying English, but still they cannot speak it. The ability to speak a language is similar with knowing that language. Speaking in a second or foreign language has often been viewed as the most demanding of the four skills. Bailey and Savage (1994) define Speaking as an "activity requiring the integration of many subsystems...all these factors combine to make speaking a second or foreign language a formidable task for language learners...yet for many people, speaking is seen as the central skill". Brown (1994) notes speaking as the most challenging skill for students because of the set of features that characterize oral discourse such as contractions, vowel reductions and elision, the use of slang and idioms, stress, rhythm and intonation, and the need to interact with at least one other speaker. The most difficult aspect of spoken English is that it is always about interaction with at least a person and when we used our second or foreign language for the first time in real interaction we get shock and disappointed with our speaking skill. We are not well prepared for spontaneous communication.

Lindsay and Knight (2006) explain that we speak for many reasons- to be sociable, because we want something, because we want other people to do something, to do something for someone else, to respond to someone else, to express our feelings or opinion about something, to exchange information, to refer to an action or event in the past, present, or future, the possibility of something happening, and so on. There are numerous daily life situations where people need speaking, such as talking to someone face to face, communicating through the phone, answering questions, asking for directions, in shops, meetings or chatting with their friends, to name a few. People spend great deal of their time interacting with more people and, each of these situations requires a different register according to the formality of the moment. Harmer (2007) says that human communication is a complex process. People need communication when they want to say something, transmit information or need to speak. Speakers use communication when they want to express or inform someone about something. They use language according to their purpose and it is necessary for there to be a listener and a speaker for effective communication. When speaking, we construct words and phrases with individual sounds, and we also use pitch change, intonation, and stress to convey different meanings.

There are many ways to promote oral skills in the classroom such as discussions, speeches and role-play which are the most typical speaking activities. Discussions are probably the most commonly activity in the oral skills class. A selected topic is given to the students through a reading, a listening passage or a videotape and then, in pairs or groups, they discuss the chosen topic in order to come up with a solution. Students will be more involved with and motivated to participate in discussions if they choose the topics in relation to their likes and dislikes.

Testing the oral proficiency of foreign language students is a complex task which may cause considerable problems at any stage of the process. The difficulties concern not only the choice of the appropriate elicitation technique and form of assessment, but they may also emerge while designing or administering the test. Ur (1995) explains that there are some things to be considered in assessing speaking such as: (1) Each general language test should include all aspects and areas of the language, therefore it should include speaking; (2) Speaking is generally considered to be the most important language skill, that is why it should take priority in any language test; (3) An oral proficiency test at the end of the course will guarantee that teachers and students devote more time to speaking practice during the course (the washback effect), otherwise a tendency to neglect extensive speaking practice or not to give it enough time and effort can be observed; (4) There are many students who speak well but 
write badly, a test based on writing may discriminate such learners and their overall assessment will not reflect their actual skills and abilities; (5) Designing valid and reliable tests that make learners improvise speech in the target language is very difficult, Speech is very difficult to assess quickly and objectively, recordings can be made but this form of evaluation is extremely time-consuming and it does not guarantee objectivity; (6) There is a problem of finding the right balance between accuracy and fluency testing. It is often not clear what criteria should be selected for assessment of the speaking skill or which should be given priority and why; (7) Even a well-balanced selection of a set of criteria does not mean that testers will apply them in an identical manner, consistent and objective assessment may be extremely difficult to reach; and (8) Oral testing is a very time-consuming procedure, students are tested individually or in pairs in real time, educational institutions have problems with ensuring the adequate amount of time for every student to be tested appropriately.

Thornbury (2007) mentions spoken test types such as (a) Interviews - learners are interviewed individually or in pairs but the formal nature of such interviews hardly ever allows for testing informal, conversational speaking styles and affects the interviewee's performance (the interviewer is also the assessor), (b) Live monologues - students present a talk or presentation on a preselected topic. The interviewer effect is then eliminated but the test provides rather restricted information on the speaker's actual skill as it does not check students' ability to handle a casual conversation. (c) Recorded monologues or dialogues - they are less stressful than live performance and give examiners more opportunities to work out consistent and possibly more objective assessment, (d) Role-plays - this test format may be particularly reliable if it matches the needs of learners and aims of the language course, however the influence of the interlocutor on the performance of the testee is hard to predict and control, and (e) Collaborative tasks and discussions - learners act as themselves, but similarly to role-plays, the testee is influenced by the interlocutor or interlocutors, the test enables examiners to assess learners' interactive skills and their ability to express personal views.

Discussion as a choice in assessing student's speaking is the focus of this paper. The discussion in this paper tries to introduce Socratic questioning method in Indonesian EFL assessment, especially in speaking skill. Socratic method is a method in teaching and learning process introduced by Socrates which stressed on self-examination through questioning. Socratic question is question introduced by Socrates which consists of six types of question such as Conceptual clarification questions, Probing assumptions, Probing rationale, reasons, and evidence, Questioning viewpoints and perspectives, Probe implications and consequences, Questions about the questions. Teachers engage students by asking questions that require generative answers. Ideally, the answers to questions are not a stopping point for thought but are instead a beginning to further analysis and research. In modeling the practice of Socrates, the teacher questions students in a manner that requires them to consider how they rationalize and respond about topics (Copeland, 2005; Paul, 2006; Chesters, 2012).

\section{METHODS}

Design of this research is descriptive qualitative. This research is designed to describe the implementation and problems faced by the lecturer in assessing student's speaking through Socratic questioning method. This research was conducted at English Department of Borneo University Tarakan, in academic year 2014/2015. Subject of the research was Fourth Semester Students of class A.

The observation used was Closed-observation. In the observation activities, the researcher acted as non-participant observer. It means, the researcher did not participate and interfere in assessing student's speaking. The aspects observed were the implementation of Socratic questioning method in assessing student's speaking. In this case, the researcher gave a checklist in every frequency of types of Socratic questions asked by the lecturer. In recording activities, the researcher recorded the lecturer and the student in speaking test. The researcher recorded the real condition in implementing Socratic Questioning method in speaking test. In interview session, the researcher asked four questions. The questions are correlated with the implementation of Socratic Questioning method in speaking test. The questions asked were about lecturer's problems in assessing student's speaking, the strengths and weaknesses in implementing Socratic Questioning method and opinion about student's speaking.

The data of this research analysed by using qualitative data analysis, code data and look for themes related to the research focus. In analyzing the data, the researcher concerned with the components of data analysis in interactive model proposed by Miles and Huberman (1984).

\section{FINDINGS AND DISCUSSION}

The result shows that the appearance of Socratic questions varied from the easiest to the most difficult. Percentage of the result shows that $25 \%$ belongs to clarification, $25 \%$ belongs to assumption, $20 \%$ belongs to reason and evidence, $15 \%$ belongs to viewpoints, $10 \%$ belongs to implications and consequences, and 5\% belongs to questions for questions.

\section{Frequency Types of 5\% Socratic Questions}

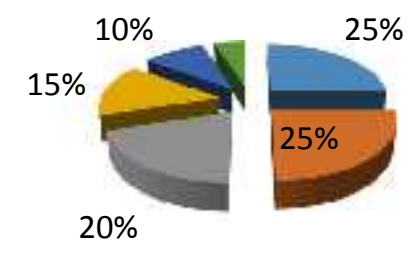

Clarification

Assumptions

Figure 1. Frequency types of Socratic Questions 
There is no doubt that raising questions is an art which requires cultivated and practiced knowledge. Asking questions is "one of the fundamental ways by which the teacher stimulates student thinking and posing questions pertinent to a specific scope of knowledge will facilitate learning process. In the field of language learning and teaching, questioning, as a teaching and learning strategy, is of immense importance and is well documented. The students' level of engagement in the process of learning largely depends on the questions formulated by the teachers in the classroom that prompt and guide thinking processes and on the questions generated by students themselves in the process of learning and teaching. Indeed, there is a developing focus among researchers upon the realization of questioning strategies as an indispensable element in developing, expanding, and challenging students' thinking. (Davoudi \& Sadeghi, 2015)

Ross (2003) explains essential components of Socratic Method: First, the Socratic Method uses questions to examine the values, principles, and beliefs of students. Second, the Socratic Method focuses on moral education, on how one ought to live. Third, the Socratic Method demands a classroom environment characterized by 'productive discomfort'. The last, the Socratic Method is better used to demonstrate complexity, difficulty, and uncertainty than at eliciting facts about the world.

Student's result in Speaking also shows result which met the lecturer expectation. It can be seen from Student's score after assessing student's speaking by using Socratic questioning method. $31 \%$ students got $\mathrm{A}, 38 \%$ got $\mathrm{B}+$, and $31 \%$ got $\mathrm{B}$.

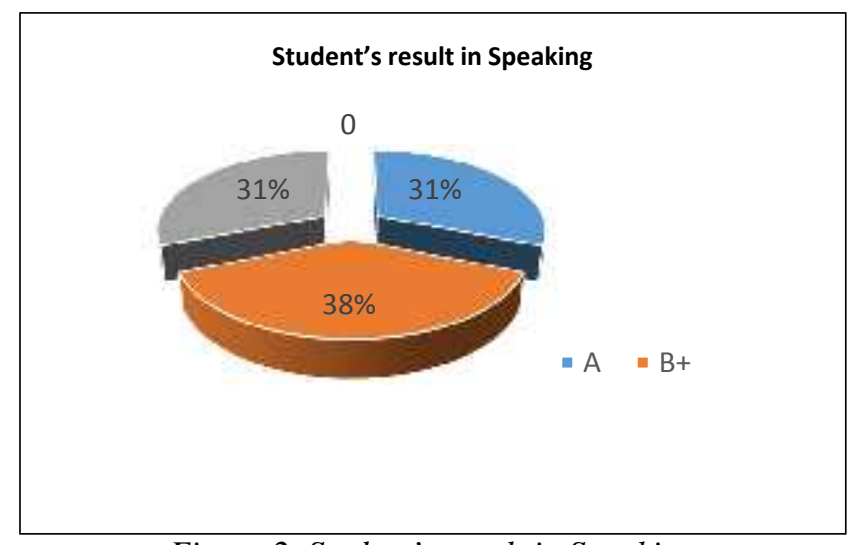

Figure 2. Student's result in Speaking

Students who got A: pronunciation was very clear and easy to understand, speech is effortless and smooth with speed that comes close to that of a native speaker, involves audience with eye contact, effective order body movement and engaged audience, Students were able to express their ideas and response with ease in proper sentence structure and tenses. Students who got $\mathrm{B}+$ : pronunciation was good and did not interfere with communication, speech is mostly smooth but with some hesitation and unevenness caused primarily by rephrasing and groping for words, much eye contact, good order body movement, effective to audience (appropriate and effective style), students were able to express their ideas and response fairly well but make mistakes with their tenses, however are able to correct themselves. Students who got B: students were slightly unclear with pronunciation at times but generally is fair, speech is slow and often hesitant and irregular, sentences may be left uncompleted, but the student is able to continue, some eye contact and order body movement, adequate to audience (appropriate use, clear meaning), students were able to express their ideas and responses adequately but often displayed inconsistencies with their sentence structure and tenses. Interview result shows that the lecturer said that Socratic questioning not only can be used to assess student's skill in speaking but also their critical thinking although some obstacles faced such as; issues selection, types of Socratic questions used in assessing, lecturer preparation, and time consuming.

Dakowska (2005) says that the actual potential of discussion activity for developing an individual learner's speaking ability can be implemented only under certain conditions such as: the topic is controversial enough to open different perspectives and interpretations, learners participate in the choice of the topic and are given enough communicative autonomy to be able to express their personal opinions and ideas, students are interested in the topic and their general knowledge is sufficient enough to discuss it (this may require appropriate preparation - studying relevant sources and processing the teacher's or peers' input), discussion is planned as a complex activity which combines working in pairs or groups and open-class or panel forms of interaction.

Furthermore, Thornbury (2007) reminds that the process of developing speaking skills consists of three stages: (1) awareness - learners are made aware of features of target language knowledge, (2) appropriation - these features are integrated into their existing knowledge-base, and (3) autonomy - learners develop the capacity to mobilize these features under real-time conditions without assistance. Learners at the advanced level of language proficiency are more likely to benefit from detailed descriptions of their speaking skills than from a single score which depicts their ability to communicate in general. The criteria used for any type of scoring usually take into account the categories of grammar, vocabulary, discourse management and interactive communication. The specific, more detailed criteria may be defined within each category with respect to the aims and character of the general evaluation procedure and the chosen spoken test format.

\section{CONCLUSION}

Testing the oral proficiency of foreign language students is a complex task which may cause considerable problems at any stage of the process. Nevertheless, it does not mean speaking test cannot be measured in correct way. Assessing should be careful and meticulous currents tests of speaking. Socratic questioning method can be considered as an alternative in assessing student's speaking. Tips for using Socratic questioning: plan significant questions that provide meaning and direction to the dialogue, use wait time; allow at 
least thirty seconds for students to respond, follow up on student's responses, ask probing questions, periodically summarize in writing key points that have been discussed, draw as many students as possible into the discussion, and let students discover knowledge on their own through the probing questions the teacher poses.

\section{REFERENCES}

Bailey, K. M. \& Savage, L. (1994). New ways in teaching speaking. USA: TESOL.

Brown, H. D. (1994). Principles of language learning and teaching. NJ: Prentice Hall Regents.

Chesters, S. D. (2012). The socratic classroom: Reflective thinking through collaborative inquiry. The Netherlands: Sense Publisher.

Copeland, M. (2005). Socratic Circles : Fostering Critical and Creative Thinking in Middleand High School.Portland,MN: Stenhouse.

Dakowska, M., (2005). Teaching English as a Foreign Language. A Guide for Professionals. Warszawa: Wydawnictwo Naukowe PWN.

Davoudi, M \& Sadeghi, M. A. (2015). A Systematic Review of Research on Questioning as a High-level Cognitive Strategy. English Language Teaching; Vol. 8, No. 10; Published by Canadian Center of Science and Education, ISSN 1916-4742 E-ISSN 1916-4750.

Harmer,J. (2007).The Practice of English Language Teaching. 4th ed. London: Longman.

Lindsay, C. \& Knight, P. (2006) Learning and Teaching English. Oxford: OUP.

Miles, M. B. \& Huberman, A. M. (1984). Qualitative Data Analysis: A Sourcebook of New Methods. California; SAGE publications Inc.

Paul, R. W. (2006). Thinker's guide to the art of Socratic Questioning. Santa Rosa, CA: Foundation for critical thinking.

Ross, V. (2003). The Socratic Method: what it is and how to use it in the classroom. Speaking of teaching: Stanford University newsletter on teaching, 13(1).

Thornbury, S.(2007). How to Teach Speaking. Harlow: Pearson Education Limited.

Ur, P.(1995). A Course in Language Teaching. Practice and Theory. Cambridge: Cambridge University Press. 